\title{
As consequências psicossociais da violência sexual
}

The consequences of violence psychosocial sexual Mary Luisa de Freitas*
Clairna Andresa Farinelli**

Resumo - O presente estudo teve como objetivo identificar quais as consequências psicossociais da violência sexual. Para tanto, a tipologia investigativa adotada foi a pesquisa bibliográfica e de campo, de abordagem qualitativa, com uma unidade de observação composta por três mulheres maiores de 18 anos, indicadas pela Rede de Atendimento a Mulheres em Situação de Violência. Como instrumento de coleta de dados foi realizada entrevista e depoimento pessoal. Verificou-se, mediante o estudo de caso, que as principais consequências psicossociais são a depressão, os sintomas essencialmente característicos do Transtorno de Estresse Pós-Traumático, tendência ao retraimento social, dificuldade de manter relacionamento amoroso e disfunção sexual. Constatou-se, também, que as vítimas abandonam o tratamento psicoterápico por não perceberem, de fato, uma intervenção por parte dos profissionais, além da angústia por trazerem à tona, em todas as sessões, as lembranças da violência sofrida.

Palavras-chave: violência; gênero; violência sexual; consequências psicossociais; disfunção sexual.

\begin{abstract}
This study aims to identify the psychosocial consequences of sexual violence. Therefore, the investigative typology adopted was the qualitative literature and field researches, with an observation unit consisting of three women over 18 years, appointed by the Assistance to Women in Situations of Violence Network. As data collection instruments, interviews and personal testimonies were used. In the case studies, it could be verified that the main psychosocial consequences are depression, symptoms essentially characteristic of post-traumatic stress disorder, a tendency towards social withdrawal, and sexual dysfunction, the difficulty of maintaining sexual relations. It was also found that the victims leave psychotherapeutic treatment for not perceiving an actual intervention by the therapists and the anguish suffered every session by bringing up memories of the violence.

Keywords: violence; genre; sexual violence; psychosocial consequences; sexual dysfunction.
\end{abstract}

\footnotetext{
* Graduada em Serviço Social. Pós-Graduanda em Residência Multiprofissional com ênfase em Urgência e Trauma no Hospital Municipal Odilon Behrens, Belo Horizontes/MG. Correspondência: Rua Argemiro Júlio, nº 298, Bairro Bela Fama, Nova Lima/MG. CEP: 34.000-000.E-mail: <maryl_paixao@hotmail.com>

** Mestre em Administração. Docente do Curso de Serviço Social da Faculdade Novos Horizontes. Correspondência: Rua Alvarenga Peixoto, 1270 - Santo Agostinho, Belo Horizonte/ MG. CEP: 30.180-121. E-mail: <clairnafa rinelli@gmail.com>
} 


\section{ADVistg all paUtg}

\} AS CONSEQUÊNCIAS PSICOSSOCIAIS DA VIOLÊNCIA SEXUAL - FREITAS, M. L.; FARINELLI, C. A. \}

DOI: $10.12957 /$ REP.2016.25400

\section{Introdução}

A violência sexual é um tema que desperta necessidade de entendimento; todavia, é um assunto difícil de ser abordado, principalmente pelas vítimas, assim, a maioria prefere o pacto pelo silêncio. A violência contra a mulher é um problema social e de saúde pública. Está atrelada aos conflitos de gênero, ou seja, provenientes da relação entre homem e mulher, em que, historicamente, o feminino exerceu um papel de subordinação ao masculino. Inserida neste contexto, a violência sexual contra a mulher é considerada atualmente uma das principais causas de morbidade no Brasil (BRASIL, 2005).

Em função disso, um maior enfoque tem sido dado às pesquisas relacionadas às consequências da violência sexual na saúde física e psíquica da mulher, a fim de servir como aparato para discussão e sensibilização dos profissionais em saúde. Entretanto, são poucos os estudos que apresentam a disfunção sexual enquanto desordem psíquica, embora ela esteja presente em grande parte das mulheres vitimadas. De igual modo, são mínimos os estudos que abordam as consequências nas relações sociais das vítimas.

Diante deste contexto, buscou-se identificar quais as consequências psicossociais da violência. Para tanto, traçamos os seguintes objetivos específicos: identificar quais os principais sintomas biopsicossociais adquiridos após a agressão e averiguar a presença de disfunção sexual nas vítimas. Acredita-se que este estudo contribuirá para a compreensão da subjetividade das mulheres após a violência sexual sofrida, além de provocar um novo olhar na abordagem durante o acolhimento e acompanhamento dessas mulheres, já que a intervenção apenas pontual constitui-se como um obstáculo ou retardo na resolução do problema. Todavia, a intervenção profissional aqui assinalada pressupõe também uma intervenção interdisciplinar, na qual a abordagem profissional do Serviço Social, somada à abordagem de outros profissionais, possibilite aos mesmos uma visão da totalidade. O intuito é assegurar uma intervenção interdisciplinar capaz de responder às demandas individuais e coletivas das mulheres vítimas de violência sexual.

\section{Violência, gênero e sexualidade}

A violência emerge de relações sociais que se modificam ao longo da história, designando realidades diversas. É reconhecida como uma categoria complexa e controversa, pois se expressa em variadas formas e contra sujeitos diferentes. De acordo com Minayo e Souza (1997, p. 514), "na verdade, só se pode falar de violências, pois se trata de uma realidade plural, diferenciada, cujas especificidades necessitam ser conhecidas". Para tanto, torna-se necessário desmistificar e desnaturalizar o conceito de vio- 


\section{ReVistg ell pautg}

\} AS CONSEQUÊNCIAS PSICOSSOCIAIS DA VIOLÊNCIA SEXUAL - FREITAS, M. L.; FARINELLI, C. A. \}

DOI: $10.12957 /$ REP.2016.25400

lência em suas mais diversas manifestações, pois este se configura como uma das expressões da desigualdade social, sendo então objeto de estudo e intervenção do assistente social.

Segundo a Organização Mundial da Saúde (2002), a violência pode ser entendida como o uso intencional da força física ou do poder, real ou como ameaça, contra si próprio, contra outra pessoa ou contra um grupo ou comunidade, que resulte ou tenha grande possibilidade de resultar em lesão, morte, dano psicológico, deficiência de desenvolvimento ou privação. Em contrapartida, Mioto (2003, p. 25) explica que, neste sentido, as manifestações da violência "são aprovadas ou desaprovadas, licitas ou ilícitas, segundo normas sociais mantidas por aparatos legais da sociedade ou por usos e costumes naturalizados".

Já, Costa (2003) alega que a violência está atrelada à força e à destrutividade, ao impulso de dominar e eliminar o outro, à pulsão de domínio. De acordo com a literatura, há duas concepções de violência: a positiva (quando é empregada em sentido favorável a alguma causa) e a negativa (demandando o seu combate e prevenção). Todavia, este estudo utilizará a concepção negativa da violência, especificamente a violência contra a mulher, restringindo-se à violência sexual. Para tanto, violência pode ser definida como o exercício de uma força ou um poder sobre o outro, contra sua vontade e sem o seu consentimento (SILVA JÚNIOR; BESSET, 2010).

A violência contra mulheres, conforme O Ministério da Saúde (BRASIL, 2002), constitui-se em uma das principais formas de violação dos seus direitos humanos, atingindo-as em seus direitos à vida, à saúde e à integridade física. Está atrelada aos conflitos de gênero, provenientes das relações entre padrões de comportamento, pensamentos e linguagens dos papéis de homem e mulher, da relação entre estes. Para Chauí (1984), este tipo de violência é uma relação de forças que converte as diferenças entre os sexos em profunda desigualdade, além de promover uma cultura que determinou papéis sociais às mulheres e aos homens, legitimando a inferioridade da mulher e a violência contra a mesma.

Usar da violência para submeter o feminino (matar em defesa da honra; estuprar; agredir fisicamente, etc.) é algo que tem sido permitido ao longo de nossa história legal. (STREY; AZAMBUJA; JAEGER, 2004, p. 71).

Deste modo, a fim de contribuir para um melhor entendimento da opressão especificamente feminina, as discussões referentes ao conceito de gênero promoveram, de acordo com Giffin (1994, p. 148), uma desconstrução das categorias sexo feminino/sexo masculino. Segundo o autor, a violência contra a mulher constitui-se como um fenômeno complexo, com raízes profundas nas relações de poder baseadas no gênero, na sexualidade e nas instituições sociais, visto que, em muitas sociedades, o direito 


\section{ADVistg all paUtg}

\} AS CONSEQUÊNCIAS PSICOSSOCIAIS DA VIOLÊNCIA SEXUAL - FREITAS, M. L.; FARINELLI, C. A.\}

DOI: $10.12957 /$ REP.2016.25400

(masculino) de dominar a mulher é considerado a essência da masculinidade.

Cabe destacar que a corrente radical do movimento feminista considera que a heterossexualidade nunca é igualitária, pois é construída em torno do prazer masculino. Assim, Cerruti e Rosa (2008, p. 3) abordam que o homem impõe sua sexualidade como sendo a sexualidade por si, e a mulher internaliza a sexualidade masculina como sendo a sua própria. Desta forma, para Verardo (1994), o controle, a dominação e até mesmo a naturalização da violência masculina na sexualidade são enfatizados, o que leva o ato sexual a ser entendido como expressão natural da necessidade do macho em conquistar (homem ativo) e dominar a fêmea (mulher passiva).

Aplicado à construção da sexualidade, funde a identidade de gênero e a identidade sexual (ser homem é praticar sexo com mulheres, e vice-versa) e resulta na hegemonia heterosexual, baseado em dois tipos de seres: homens ativos sexualmente e mulheres passivas sexualmente. [...] O homem vai fazer e à mulher será feito. (VERARDO, 1994, p.15-16).

Observa-se, então, a reificação da mulher, a partir do momento em que lhe é atribuída a função de objeto propiciador da satisfação sexual do homem. A partir disso, pode ser entendida a problemática da violência sexual, que será melhor aprofundada nas linhas subsequentes.

\section{Violência sexual}

De acordo com o Fórum Brasileiro de Segurança Pública (2013), os casos de estupro estão crescendo. Os dados apontam que, em 2011, foram registrados 43.869 crimes deste tipo, enquanto que em 2012 ocorreram 51.101 casos. Entretanto, cabe frisar que estes números são subestimados, considerando que só $10 \%$ das vítimas de abuso sexual denunciam a violação. O Ministério da Saúde (BRASIL, 2002) define violência sexual como sendo toda relação de poder, realizada por meio da força física, coerção ou intimidação psicológica, em que uma pessoa obriga outra ao ato sexual contra sua vontade. Ocorre em uma variedade de situações, como estupro, sexo forçado no casamento, entre outros.

Existem várias terminologias genéricas para caracterizar os crimes sexuais, todavia, segundo Drezett (2000) as mais utilizadas são violência sexual, agressão sexual e abuso sexual. Contudo, para o autor, o mais aceitável é o termo violência sexual, por ter uma conotação mais ampla. O termo abuso sexual restringe-se aos casos em que não ocorreram penetrações vaginais ou quando as vítimas são crianças. Porém, o termo mais utilizado pelas vítimas de violência sexual é estupro, que, de acordo com o artigo 213 do Código Penal (BRASIL, 1940), consiste em constranger alguém, 


\section{ReVistg ell pautg}

\} AS CONSEQUÊNCIAS PSICOSSOCIAIS DA VIOLÊNCIA SEXUAL - FREITAS, M. L.; FARINELLI, C. A. \}

DOI: $10.12957 /$ REP.2016.25400

mediante violência ou grave ameaça, a ter conjunção carnal ou a praticar ou permitir que com ele se pratique outro ato libidinoso.

A violência sexual é um crime que atinge as mulheres de todas as idades e raças. É considerada, atualmente, como uma das principais causas de morbidade no Brasil (BRASIL, 2005). Já para Drezett (2003, p. 36) a violência sexual apresenta-se como uma das mais antigas e amargas expressões da violência de gênero, além de representar uma inaceitável e brutal violação dos direitos humanos. Ao agressor geralmente é atribuída a imagem de uma pessoa desconhecida; contudo, na maioria dos casos, é alguém conhecido e próximo da mulher, até mesmo seu companheiro.

Reproduzindo as ideias de Drezett (2003), Costa e Santos (2008) afirmam que uma parcela considerável da população feminina já sofreu agressão sexual por um parceiro íntimo. Entretanto, o estupro doméstico ainda não é reconhecido no Código Penal Brasileiro. Segundo as autoras, as mulheres que experimentam tais situações nem sempre percebem essa vivência como uma violência, pois interiorizam a ideia de que, no casamento, sexo é uma obrigação.

Neste sentido, Dantas-Berger e Giffin (2005) enfatizam que uma ordem social de tradição patriarcal por muito tempo consentiu certo padrão de violência contra mulheres, uma vez que designou ao homem o papel ativo na relação social e sexual, em detrimento da sexualidade feminina, limitando-a à passividade e à reprodução. Não obstante, a dependência financeira feminina parecia explicar a aceitação de seus deveres conjugais, que incluíam os serviços sexuais. Destarte, de acordo com as explicações de Verardo (1994, p. 6), esta ordem social de tradição patriarcal

[...] estabelece coisas absurdas como, por exemplo, entre as funções da mulher casada está a de ter relações com seu marido, quando ele o desejar, independente dela o desejar. Submeter-se a uma relação sexual sem vontade é a mesma coisa que sofrer um estupro.

A fim de prevenir, punir e erradicar a violência contra a mulher do âmbito doméstico e intrafamiliar, em 2006 foi promulgado a Lei $\mathrm{n}^{\underline{0}}$ 11.340 (BRASIL, 2006), também conhecida como Lei Maria da Penha, definindo a violência como: física, patrimonial, sexual, moral e psicológica. Contudo, em uma sociedade machista, justifica-se a violência sexual das formas mais variadas. $\mathrm{O}$ agressor é considerado comumente como um anormal psíquico, doente mental, alcoólatra, viciado em drogas etc., alguém que não consegue controlar sua necessidade sexual. Assim, observa-se, por parte dos agressores, a naturalização da violência como produto da conduta humana, movida pelo instinto e não pela razão (COSTA, 2003, p. 36).

Giffin (1994, p. 15-16) ainda aborda a problemática da culpabilização da vítima. Considerando que é preciso encontrar uma explicação moral para o estupro, a mulher é que vai ser acusada de ser muito provocante. Então a mensagem passada é a de que, se a mulher quer se proteger 


\section{ADVistg all pavtg}

\} AS CONSEQUÊNCIAS PSICOSSOCIAIS DA VIOLÊNCIA SEXUAL - FREITAS, M. L.; FARINELLI, C. A. \}

DOI: $10.12957 /$ REP.2016.25400

de um estupro, deve se comportar bem, vestir-se descentemente e não andar sozinha à noite nas ruas. Caso contrário, ela é quem seria responsável pelo estupro.

Uma concepção similar à afirmativa supramencionada surpreendeu de forma negativa a sociedade brasileira a partir de uma pesquisa realizada pelo Instituto de Pesquisa Econômica Aplicada (Ipea). De acordo com os resultados, $58 \%$ da população concordam, total ou parcialmente, com a afirmação de que, se mulheres soubessem se comportar, haveria menos estupro. Por trás desta assertiva está a noção de que os homens não conseguem controlar seus impulsos sexuais; então, as mulheres, que os provocam, é que deveriam saber se comportar, e não os estupradores. Entretanto, de acordo com o Ipea houve um erro e os dados tiveram alterações (IPEA, 2014).

\section{Atuação do assistente social no âmbito da violência sexual}

O Serviço Social é uma profissão historicamente determinada e possui, em sua gênese, uma ligação intrínseca com as relações sociais (antagônicas e contraditórias) que se constituíram com o advento do capitalismo (VELLOSO, 2013, p. 48). Segundo a autora, embora a profissão tenha se mantido aliada aos interesses da classe dominante até meados dos anos 1960, com o surgimento do movimento de reconceituação, o Serviço Social conquistou um amadurecimento. Desse modo, foi levado a repensar a sua atuação, assim como a mudar o foco do Projeto Ético-Político para a resolução dos problemas sociais da classe trabalhadora, mediante uma postura crítica e questionadora.

A profissão de assistente social foi regulamentada pela Lei 8.662/ 93 (BRASIL, 2012), cujo agir profissional pautou o Código de Ética da Profissão, de modo a: atuar na defesa intransigente dos direitos humanos inerentes aos usuários, assim como na perspectiva do Projeto Ético-Político da profissão, visando a uma nova ordem societária, que se dá no reconhecimento do sujeito enquanto sujeito de direitos. Embora a violência sexual se apresente como um desafio profissional para o assistente social, o mesmo possui conhecimento teórico-metodológico, ético-político e técnico-operativo para intervir nas várias expressões da questão social, conforme explica lamamoto (2010, p. 19):

O Serviço Social na contemporaneidade teve o desafio de decifrar os novos tempos, que exigiu um profissional qualificado, não sendo apenas crítico e reflexivo, mas com suporte teórico e metodológico para embasar-se em suas criticas e diante da realidade, construir propostas de trabalhos criativos [...].

O assistente social é um profissional que possui qualificação e conhecimento complexo para intervir nas diversas faces da violência. 


\section{ReVistg ell pautg}

\} AS CONSEQUÊNCIAS PSICOSSOCIAIS DA VIOLÊNCIA SEXUAL - FREITAS, M. L.; FARINELLI, C. A. \}

DOI: $10.12957 / R E P .2016 .25400$

Inicialmente, tal profissional necessita produzir um conhecimento da realidade, entendendo as causas/raízes do problema. Utilizando seus instrumentais técnicos, em seguida passará a adotar formas de intervenção que possam amenizar ou solucionar a situação. Para tanto, observa-se que o artigo $4^{\circ}$ do Código de Ética da Profissão (BRASIL, 2012) define como competência do assistente social a orientação de indivíduos e grupos de diferentes segmentos sociais no sentido de identificar recursos e de fazer uso dos mesmos no atendimento, como também na defesa dos direitos do usuário.

O Serviço Social, enquanto profissão inserida nas relações sociais, desempenha um papel preponderante no desenvolvimento de ações, estudos e pesquisas referentes ao combate à violência. Para realização dessas competências e atribuições, requer a utilização de instrumentais que serão adequados a cada situação social enfrentada pelo profissional. Lembramos que o uso dessas técnicas e estratégias não deve contradizer os objetivos e competências da profissão, uma vez que estes instrumentos devem ser utilizados com uma perspectiva de humanização dos atendimentos, integração social e defesa de direitos.

Para Biella (2005, p.36), a ação profissional do assistente social na problemática da violência contra a mulher necessita de bases teóricometodológicas pautadas em conhecimentos referentes aos "direitos das muIheres, às políticas públicas existentes para a erradicação e o combate à violência e as construções dos papéis sociais". Como já observado por lamamoto (2010, p. 20), o assistente social precisa desenvolver a capacidade de decifrar a realidade e "construir propostas de trabalhos criativas capazes de preservar e efetivar direitos, a partir de propostas emergentes do cotidiano".

Mioto (2003, p. 102) contribui com as explicações de Biella (2005) ao abordar que, para que o assistente social aja no âmbito da violência contra mulher, não basta compreender a existência dos elementos que constroem este fenômeno nem as teorias explicativas que lhe dão sustentação. É preciso conhecer profundamente o objeto sobre o qual se trabalha, a fim de captar todas as inter-relações possíveis entre as diferentes dimensões e a forma como elas se articulam. Através dessa metodologia se estabelecerão condições para o desenvolvimento de ações profissionais numa perspectiva crítica, visando ao fim deste tipo de violência.

Outro fato igualmente importante ressaltado por Biella (2005) é que, considerando a violência contra a mulher como fruto das desigualdades de gênero, o combate a essa desigualdade requer mudanças nas relações de poder. Além disso, para a igualdade ser alcançada é primordial que as mulheres também tenham acesso ao poder, fazendo-se necessário o empoderamento das mesmas como um caminho para igualdade. O termo empoderamento pode ser definido, segundo Forward ${ }^{1}$ (apud BIELLA, 2005), como "todo o acréscimo de poder que, induzido ou conquistado, permite

${ }^{1}$ Ver: S. Forward (1989). 


\section{ADVistg all paUtg}

\} AS CONSEQUÊNCIAS PSICOSSOCIAIS DA VIOLÊNCIA SEXUAL - FREITAS, M. L.; FARINELLI, C. A. \}

DOI: $10.12957 /$ REP.2016.25400

aos indivíduos ou unidades familiares aumentarem a eficácia do seu exercício de cidadania".

O empoderamento supramencionado compreende três esferas: a social, que diz respeito ao acesso da mulher ao conhecimento, à informação, à participação em organizações sociais e aos recursos financeiros; a esfera política, baseada no processo de tomada de decisões que afetam o futuro da mulher, como a participação das decisões coletivas; e, por fim, a esfera psicológica, que se refere à capacidade da mulher em tomar suas próprias decisões e ter controle sobre sua vida.

Contudo, para que este empoderamento (social, político e psicológico) seja alcançado, geralmente há necessidade de agentes externos que intervenham como mediadores e catalisadores para desenvolvê-lo. Desta forma, o assistente social é chamado a intervir, a fim de contribuir com este processo através do atendimento e acompanhamento individual, em coordenação de grupos de apoio ou no planejamento, gestão e execução de políticas públicas voltadas para essas mulheres. Diante do exposto, o assistente social tem, nesta problemática, um novo espaço de atuação profissional, no qual pode oferecer caminhos e possibilidades, viabilizar direitos e ampliar a cidadania por meio de uma melhor qualidade de vida.

Segundo Guerra (2011), a complexidade da diversidade alcançada pela intervenção profissional, objetivando atender às demandas e requisições oriundas das relações sociais, coloca a dimensão instrumental do assistente social como a mais desenvolvida da profissão, portanto, capaz de indicar as condições e possibilidades da mesma.

Todavia, essa intervenção profissional aqui assinalada pressupõe também uma intervenção interdisciplinar, na qual a abordagem profissional do Serviço Social, somada à abordagem de outros profissionais, possibilite aos mesmos uma visão da totalidade. O intuito é assegurar uma intervenção interdisciplinar capaz de responder às demandas individuais e coletivas das mulheres vítimas de violência sexual. De acordo com Ely (2003), e tendo em vista que as demandas do Serviço Social estão cada dia mais complexas, essa profissão deve buscar novas formas de executar seu trabalho, de modo a direcionar o envolvimento com a área interdisciplinar. Ou seja, um espaço de troca mútua entre várias especificidades do conhecimento, agregando ciência no fazer profissional e propiciando o desvendamento da complexidade de suas demandas, bem como ultrapassar seus limites profissionais.

A prática da interdisciplinaridade também é incentivada pelo Código de Ética da profissão, no Capítulo III, artigo 10, alínea d: "incentivar, sempre que possível, a prática profissional interdisciplinar" (BRASIL, 2012, p. 33). Nesta prerrogativa, a participação em equipes interdisciplinares é exposta como um dever profissional, que deverá ser sempre cumprido quando houver possibilidade. Esse dever também está relacionado com um dos princípios fundamentais do referido código, o compromisso com a qualidade 


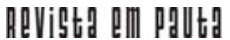

\} AS CONSEQUÊNCIAS PSICOSSOCIAIS DA VIOLÊNCIA SEXUAL - FREITAS, M. L.; FARINELLI, C. A. \}

DOI: $10.12957 / R E P .2016 .25400$

dos serviços prestados aos usuários, bem como o aprimoramento intelectual, numa perspectiva de competência profissional (ELY, 2003).

A partir das explicações de Marques e Ramalho (2002), observase que, em uma equipe interdisciplinar, o Serviço Social trabalha com os demais profissionais de forma participativa, buscando contribuir com seus conhecimentos teórico-metodológicos que fazem parte de sua disciplina no estudo e superação de determinas situações. Para tanto, torna-se imprescindível ao assistente social conhecer as consequências psicossociais da violência sexual, pois, no momento de sua intervenção junto às vítimas, estas consequências podem ir de encontro ao que é proposto pelo profissional.

\section{Consequências psicossociais da violência sexual}

Para uma melhor abordagem das consequências psicossociais da violência sexual feminina, é necessário realizar uma reflexão sobre a concepção do termo trauma. De acordo com as explicações de Souza (2013, p. 28), o indivíduo, ao passar por um estresse traumático (situação de ameaça à vida ou forte emoção), a princípio teria duas opções, lutar ou fugir. Entretanto, conforme a autora, ainda existe uma terceira opção, a de congelarse diante do perigo que julga estar enfrentando como uma reação à situação. A partir deste processo de congelamento da energia que não foi descarregada após o evento, pode ser provocado o trauma, uma vez que persiste no organismo um impacto não resolvido, uma energia não descarregada (SOUZA, 2013, p. 29).

Cada pessoa reage de um modo singular às situações de agressão. Segundo Scarpato (2004), uma pessoa pode ficar com medo apenas por alguns dias e depois voltar à vida normal, outra não conseguirá voltar à sua rotina por um longo espaço de tempo e uma terceira pode afundar numa profunda depressão devido ao abalo causado pela experiência. A violência sexual é classificada, de acordo com a quarta revisão do Manual diagnóstico e estatístico de transtornos mentais (DSM IV, 1995), como um extremo estressor traumático envolvendo experiência pessoal direta. Este tipo de violência expõe a mulher a sérios problemas físicos e consequências de ordem psicológica e social. Aprofundaremos essas questões a seguir.

\subsection{Depressão}

Estado de humor deprimido. A depressão, traduzida por insegurança, baixa autoestima e sentimento de culpa e de inferioridade em muIheres vítimas de violência sexual, provoca uma diminuição do interesse e participação em atividades significativas da vida (WALDO FILHO; SOUGEY, 2001). 


\section{ADVistg all paUtg}

\} AS CONSEQUÊNCIAS PSICOSSOCIAIS DA VIOLÊNCIA SEXUAL - FREITAS, M. L.; FARINELLI, C. A.\}

DOI: $10.12957 /$ REP.2016.25400

\subsection{Transtorno de Estresse Pós-Traumático}

De acordo com Waldo Filho e Sougey (2001, p. 222), em 1980 a Associação Psiquiátrica Americana publicou a "terceira revisão de sua classificação diagnóstica de transtornos mentais, o Manual de Diagnóstico e Estatística dos Distúrbios Mentais (DSM-III)", na qual emergiu o novo termo diagnóstico Transtorno de Estresse Pós-Traumático (TEPT), propiciando o reconhecimento do sofrimento de pessoas cuja história traumática não era valorizada como fator determinante de seus padecimentos. Para diagnosticar o TEPT, os sintomas devem persistir por mais de um mês após a ocorrência do trauma e causar sofrimento ou prejuízo significativo ao funcionamento social, ocupacional ou em outras áreas importantes da vida do indivíduo (DSM-IV, 1995). O TEPT é o principal transtorno psiquiátrico associado aos acidentes e violências, cujos sintomas dividem-se em três grandes grupos:

a) Reexperiência traumática: consiste na reexperimentação do evento traumático de várias maneiras. Em regra, a pessoa tem recordações recorrentes e intrusivas do evento, tais como sonhos aflitivos, pesadelos, flashbacks e pensamentos/lembranças espontâneas e involuntárias que não se alteram com o tempo, carregadas de forte componente afetivo e emocional, trazendo angústia e sofrimento intensos (WALDO FILHO; SOUGEY, 2001). Essas recordações intrusivas normalmente provocam "sentimentos de medo, terror, raiva, impotência, vulnerabilidade, vergonha, tristeza e culpa", conforme as explicações de Figueira e Mendlowicz (2003, p. 14);

b) Esquiva e distanciamento emocional: para evitar o sofrimento causado pela reexperiência traumática, as vítimas utilizam diversas estratégias de fuga; surge, assim, o segundo grupo de sintomas. Filho e Sougey (2001) explicam que estas estratégias de fuga apresentam-se de formas óbvias ou sutis, que vão da "recusa em falar sobre o trauma, ao uso de bebidas alcoólicas ou drogas para obscurecer as memórias, até ao engajamento excessivo e compulsivo em atividades como trabalho, jogo, sexo, entre outras" (FILHO; SOUGEY, 2001, p. 223);

c) Hiperexcitabilidade psíquica: os sintomas deste último grupo são facilmente notáveis e estão atrelados "à excitação aumentada e sintomas relacionados com distúrbios de sono, irritabilidade, dificuldade de concentrar-se, hipervigilância e reação de susto exagerada" (CASSADO; GALLO; ALBUQUERQUE, 2003, p. 104). Outras queixas sintomáticas podem acompanhar o estado de hiperexcitabilidade, como: taquicardia, sensação de oco na cabeça, respiração curta ou suspirosa, formigamentos, sudorese, peso no estômago, extremidades frias, cefaleias, tonturas, dentre outras (FIGUEIRA; MENDLOWICZ, 2003, p. 16). 


\subsection{Retraimento social}

Geralmente inicia-se logo após o evento traumático. Segundo a DSM-VI (1995), o indivíduo pode queixar-se de acentuada diminuição do interesse ou da participação em atividades anteriormente prazerosas, bem como o sentimento de estar deslocado ou afastado de outras pessoas. Um dos fatores que contribuem para o retraimento social são as estratégias utilizadas pelas vítimas para fugir de quaisquer conversas, situações e atividades associadas ao trauma, como um mecanismo de defesa contra a ansiedade e angústia gerada pelo fenômeno intrusivo (WALDO FILHO; SOUGEY, 2001, p. 223).

\subsection{Dificuldade de manter um relacionamento amoroso}

De acordo com a DSM-IV (1995), as vítimas de violência sexual possuem uma capacidade acentuadamente reduzida de sentir emoções, especialmente aquelas associadas com intimidade, ternura e sexualidade. Esta dificuldade pode estar atrelada ao sentimento de futuro abreviado advindo do TEPT.

Para Waldo Filho e Sougey (200, p. 223), a visão do futuro se traduziria como algo comprovadamente incerto, imprevisível, inseguro e perigoso, sensações que suscitam a pergunta do porquê investir ou se envolver, pois a ameaça traumática estaria ainda viva na lembrança e no comportamento. Para tanto, melhor "não pensar, não sentir e não planejar".

\subsection{Disfunção sexual}

A sexualidade é considerada como um dos pilares da qualidade de vida do ser humano. Contudo, empiricamente, acredita-se que a violência sexual pode deixar marcas permanentes na vida sexual de uma mulher (PEREIRA, 2007). De acordo com Souza et al. (2013, p. 102), o TEPT pode ser o mediador entre a violência sexual e o desenvolvimento de transtornos sexuais. Segundo os autores, "as vítimas geralmente apresentam maior insatisfação sexual, perda de prazer, medo e dor, sintomas que podem permanecer após anos da violência".

A fim de investigar o funcionamento sexual de mulheres após a violência sexual, foi realizada, por Berlo e Ensink (apud SOUZA et al., 2013), entre 1979 e 1999, uma meta-análise, cujos estudos mostraram diminuição da satisfação sexual imediata após o estupro, retornando aos níveis prévios após alguns meses. Entretanto, outros estudos verificaram que, mesmo após alguns anos depois da ocorrência, havia queda na satisfação e no prazer durante as relações sexuais por parte expressiva das muIheres. Identificou-se, também, o desenvolvimento de medo do sexo, perda do interesse sexual, bem como indiferença a assuntos e atividades sexuais. 


\section{ADVistg all paUtg}

\} AS CONSEQUÊNCIAS PSICOSSOCIAIS DA VIOLÊNCIA SEXUAL - FREITAS, M. L.; FARINELLI, C. A.\}

DOI: $10.12957 /$ REP.2016.25400

Todavia, segundo Souza et al. (2013, p. 102), em algumas pesquisas "as vítimas mostraram maior freqüência de relações sexuais, na tentativa de adquirir controle sobre a própria vida sexual". Emoções sentidas durante e imediatamente após a violência sexual são consideradas fortes mediadores da permanência das disfunções sexuais (SOUZA, 2013, p. 54).

\section{Metodologia}

A tipologia investigativa adotada neste trabalho foi a pesquisa bibliográfica e de campo, de abordagem qualitativa. A unidade de observação foi composta por três mulheres, maiores de 18 anos, indicadas pela Rede de Atendimento a Mulheres em Situação de Violência, as quais serão identificadas por E1 (entrevistada 1), E2 (entrevistada 2) e E3 (entrevistada 3). Foram excluídos os casos nos quais a violência foi perpetrada em tempo inferior ou igual a 18 meses. O tempo previsto para aplicação dos instrumentos foi cerca de uma hora e meia. Entretanto, tendo em vista tratar-se de um assunto delicado, foi necessário conceder um tempo maior para duas das entrevistadas.

A coleta de dados deu-se por meio de entrevista e depoimento pessoal, realizados no mês de outubro de 2014. As entrevistas foram realizadas na residência das participantes, em um local reservado, a fim de garantir o sigilo das informações. Inicialmente, foi dado um depoimento pessoal; em seguida, foi aplicada a Escala Post-Traumatc Stress Disorder Checklist (PTSD CheckList PCL-C), um questionário que visa avaliar a presença dos sintomas associados aos critérios B, C e D do DSM-IV (pensamentos intrusivos/reexperiências, evitação e hiperexcitação).

A análise qualitativa dos dados foi feita por meio de leitura da transcrição das entrevistas e depoimento pessoal. A coleta de dados foi precedida de assinatura do Termo de Consentimento Livre e Esclarecido.

\section{Caracterização da unidade de observação}

\section{Caso 1}

E1 (40 anos) reside no município de Nova Lima. Aos 34 anos foi vítima de estupro perpetuado pelo companheiro. Devido ao alcoolismo do marido, estavam em situação de separação de corpos no momento da agressão. Certa noite, seu companheiro entrou no quarto onde ela dormia e, puxando-a pelas pernas, levou-a até o quarto dele. Ela relatou ter ficado perplexa com tudo o que estava acontecendo; a única reação que teve foi a de travar a região pélvica, o que acarretou laceração vaginal.

Os vizinhos seguraram o marido até a chegada da polícia. Contudo, ele ficou detido somente por três dias. Ela teve que conviver com o 


\section{ReVistg ell pautg}

\} AS CONSEQUÊNCIAS PSICOSSOCIAIS DA VIOLÊNCIA SEXUAL - FREITAS, M. L.; FARINELLI, C. A. \}

DOI: $10.12957 / R E P .2016 .25400$

agressor por mais uma semana dentro da mesma casa. O sentimento de revolta e raiva pela agressão sofrida era imensurável e, neste período de sete dias de convivência, por duas vezes ela tentou envenená-lo. Transformouse numa pessoa muito agressiva, pensando várias vezes em pagar alguém para matá-lo.

E1 relatou que não conseguia dormir, assustava-se com qualquer barulho dentro de casa, ouvia vozes na rua e já pensava que era ele. Vinha na mente o rosto dele, de modo que ela tremia, sentia dores abdominais, náuseas, dor de cabeça, dentre outros. Dirigia-se ao trabalho, porém passava mal, pois já não conseguia se alimentar direito. Quando dormia tinha pesadelos recorrentes com a agressão vivenciada.

Após a separação, a fim de se livrar das lembranças do que ele tinha feito, queimou a cama e o colchão. Não dormiu mais no mesmo quarto onde ele a estuprou, e só não mudou de casa porque não tinha condições. Ficou com vergonha dos vizinhos e tem vergonha de não ter conseguido reagir e evitar o que aconteceu. Para E1, a vida começou a perder o sentido; não queria mais se arrumar, não sentia vontade de ver pessoas, mandava avisar às visitas que estava dormindo ou tinha saído.

Após alguns meses, E1 iniciou uma vida promíscua, com atitudes sadomasoquistas nas relações sexuais, pois não conseguia manter uma relação com troca de carícias. Cinco anos mais tarde, e até hoje, ela não consegue manter certos tipos de relação sexual e/ou em determinadas posições. Houve um aumento no número de relações sexuais (quanto mais fazia sexo, mais queria). Ela fazia de tudo, porém eles não podiam tocá-la de forma alguma. Assim ela se vingava dos homens (queimando com vela, açoitando, algemando). Gostava de se sentir na posição do homem; isso a satisfazia.

Iniciou acompanhamento psicoterápico que foi interrompido, pois, segundo ela, tinha que contar a mesma história, reviver o passado com muito choro. Frequentou por seis meses, entretanto, continuava tendo pesadelos, sentindo medo e distante de todos. No momento, faz uso de antidepressivos e, quando fica sabendo que o ex-marido está no bairro, apavora-se. Evita os lugares onde ele possa estar. Vai à igreja com menos frequência (uma vez ao mês) e, se antes frequentava muitos lugares, agora prefere não sair para não correr o risco de encontrá-lo.

\section{Caso 2}

E2 (41 anos) reside no município de Belo Horizonte. Aos 27 anos foi vítima de estupro perpetuado por um desconhecido. No dia da agressão, participava de uma festa com amigos. Como precisava ir embora, pegou carona com um rapaz, entretanto, o rapaz tomou outra rota e a levou para um local ermo e escuro, onde a estuprou. E2 ficou paralisada, sem conseguir acreditar no que estava acontecendo, sentiu nojo e chorou muito na hora da agressão. 


\section{ADVistg all paUtg}

\} AS CONSEQUÊNCIAS PSICOSSOCIAIS DA VIOLÊNCIA SEXUAL - FREITAS, M. L.; FARINELLI, C. A. \}

DOI: $10.12957 /$ REP.2016.25400

Após o ocorrido, E2 não quis procurar um hospital ou delegacia, pois sentia muito medo e vergonha do que tinha acontecido. Não conseguia dormir e não sentiu fome no dia posterior. Até o momento, E2 não comunicou aos familiares que foi vítima de estupro, somente desabafou com duas amigas. Segundo ela, não tem coragem de contar, porque seus familiares sofreriam muito com tudo isso. Ainda tem muita vergonha de comentar o assunto, portanto prefere se calar.

Para E2, o estupro foi a destruição de um sonho, pois, embora não fosse virgem na época da violência, estava se guardando para uma relação sexual com alguém que a amasse, e não algo feito de uma forma tão brutal. Relatou que se sente seguida na rua e o medo toma conta de si. Não sai mais sozinha à noite, frequenta somente festas de familiares ou vai à igreja. Afastou-se de alguns amigos para que não descobrissem o que havia acontecido. Teve depressão, mas interrompeu o tratamento psicoterápico porque sentia muita vergonha de tocar no assunto, já que durante as sessões tinha que comentar os fatos.

Desde então passaram-se quatorze anos, mas ela ainda não conseguiu manter um relacionamento amoroso, pois as lembranças do fato ainda são dolorosas. Não consegue confiar nos homens, acredita que eles se aproximam dela só para manter relações sexuais, e isso a deixa com medo. Acredita que nunca encontrará alguém que a ame de verdade. Para ela, homens não têm domínio sobre os desejos e não conseguem amar uma mulher de verdade. Ainda hoje, as lembranças do estupro sempre vêm em seus pensamentos e isso a machuca, logo chora e quer ficar sozinha.

\section{Caso 3}

E3 (31 anos) reside no município de Contagem. Aos 12 anos foi vítima de estupro perpetuado por desconhecido. Ela estava dormindo em sua residência, junto com sua mãe, irmã e tia, quando foram surpreendidas na madrugada por um homem que invadira o local com a intenção de roubar. Como elas não possuíam dinheiro, informaram isso ao sujeito, que aceitou o fato. Porém, ele iria embora levando E3 como garantia de que as outras mulheres não chamariam a polícia. Segundo ele, quando chegasse à esquina a soltaria para retornar para casa.

O homem a pegou pela mão e foi andando e conversando com ela pela rua, de modo que eles pareciam dois namorados. Ela tinha o corpo bastante desenvolvido para a idade. Ao chegar à esquina, ele a obrigou a entrar em um fusca branco e pediu que ela fosse para baixo do banco de trás. Percorreu certa distância, parou o carro em uma rua escura, em frente a um ferro velho. Ela estava usando uma camisola transparente e ele retirou sua calcinha enquanto ia explicando o que iria acontecer. Explicou até que doeria um pouco quando o hímen se rompesse. Puxou-a para o banco da frente e, utilizando força física e portando duas armas de fogo, estuproua. Ele pediu para que ela ficasse em certas posições que ela não sabia, ent- 


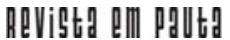

\} AS CONSEQUÊNCIAS PSICOSSOCIAIS DA VIOLÊNCIA SEXUAL - FREITAS, M. L.; FARINELLI, C. A. \}

DOI: $10.12957 / R E P .2016 .25400$

ão dizia que, se não fizesse do jeito que ele queria, daria um tiro na cara dela.

Depois de um tempo, o homem deu mais algumas voltas com o carro e novamente parou em outro local ermo. Foram mais algumas horas de estupro. E3 era muito inocente, não entendia porque ele a pedia para fazer algumas coisas ou ficar em algumas posições. Por fim, com o rosto tampado com uma blusa de frio, mãos amarradas, de camisola e sem calcinha, E3 foi deixada em uma rua. Posteriormente, E3 encontrou um casal na rua e pediu ajuda. Levaram-na para delegacia, onde se sentiu constrangida porque olhavam para ela com olhar diferente e a pressionaram para que ela declarasse que na verdade estava com um namoradinho. Foi uma tortura. Até no IML E3 se sentiu humilhada, porque a reviravam como se fosse um animal, abrindo e fechando suas pernas.

Sentiu nojo de si mesma, além de se sentir a mais feia, a mais suja, a mais fedida; decidiu tomar banho com água sanitária. Chorava todas as noites. Até hoje, ela se sente culpada e não sabe dizer o porquê. Ficou muitos anos sem conversar com a mãe e a irmã porque estava revoltada; escondeu-se do mundo, tinha atitudes agressivas. Teve depressão, o cabelo caiu, não comia direito. Sofreu muito com as lembranças e os pesadelos. Dos 13 aos 18 anos evitou tocar no assunto da violência.

Depois de 19 anos E3 ainda tem resistência em entrar em fusca e frequentar o bairro Venda Nova, onde ocorreu o estupro. Isso faz com que ela se lembre do fato e os sentimentos de tristeza surgem. Ficou sem coragem de manter relação sexual dos 14 aos 16 anos de idade. Aos 17 teve a primeira relação sexual em um relacionamento amoroso. Adquiriu compulsão sexual e gosta de sexo com sadismo. Tem necessidade de mostrar para o homem que ela não é santinha. Podem ser vários numa noite, ela não se sente constrangida. Quando o homem fala que não dá conta, isso a satisfaz. Não gosta que as relações sexuais sejam carinhosas, pois carícias demais a irritam. Em alguns homens, o cheiro, a forma de conversar ou o jeito a fazem lembrar-se do estuprador. Já tomou nojo de amigos por isso.

Segundo E3, para evitar que os homens a usem, ela os usa primeiro. Acredita que não conseguirá manter um relacionamento porque eles sempre vão machucá-la. Não se permite apaixonar-se, não consegue demonstrar sentimento; assim, evita o sofrimento. Às vezes frequenta a igreja evangélica para impor um limite a si mesma, porque quando deixa de frequentá-la, fica sem pudor, sem limites.

Faz uso de antidepressivos. Interrompeu o acompanhamento psicoterápico, já que, segundo ela, o psicólogo ficava olhando para os seus seios e ela sentia muito ódio disso. Ainda hoje, por vezes, sente o cheiro do sujeito em seu corpo, então toma banho com água sanitária. 


\section{ADVistg all paUtg}

\} AS CONSEQUÊNCIAS PSICOSSOCIAIS DA VIOLÊNCIA SEXUAL - FREITAS, M. L.; FARINELLI, C. A.\}

DOI: $10.12957 /$ REP.2016.25400

\section{Discussão dos resultados}

Mediante as entrevistas, evidenciou-se que a reação de E1, E2 e E3 ao evento traumático (violência sexual) foi de paralisia e inércia, um congelamento de energia. Neste sentido, Souza (2013, p. 28-29) explica que o indivíduo, ao passar por uma situação de ameaça à vida ou de forte emoção, além de ter a opção de lutar ou fugir, pode reagir de uma outra maneira, congelando-se diante do perigo que julga estar enfrentando. Este congelamento de energia é uma reação à situação enfrentada; entretanto, esta energia não descarregada após o evento pode acarretar o trauma, uma vez que persiste no organismo um impacto não resolvido (evento traumático).

Identificou-se, a partir dos relatos de E1, E2 e E3, que a violência sexual sofrida desencadeou consequências de ordem psíquica e social, as quais interferem significativamente em seu dia a dia. De acordo com Andrade, Viana e Silveira (2006), a violência sexual é a causa também de agravos na saúde mental das mulheres que a vivenciam, cujos casos mais relatados são depressão e Transtorno de Estresse Pós-Traumático. Para o Ministério da Saúde (BRASIL, 2002), as referidas consequências influenciam na capacidade que as vítimas têm de agir, de participar plenamente, limitando o seu desenvolvimento pessoal, profissional e afetivo. Isso demonstra que a violência traz implicações sociais às mulheres, limitando a sua participação na esfera produtiva da sociedade.

Percebeu-se que E1, E2 e E3 assumem equivocadamente a responsabilidade pela agressão e generalizam os sentimentos de angústia, culpa e vergonha. Na concepção de Foucault (1999), esta culpa é muitas vezes reforçada pelo senso comum, no qual a própria vítima está inserida, que a responsabiliza por provocar a agressão, por ser incauta à abordagem do agressor.

A gente dormia em quartos separados [...], eu evitava sair do banho de calcinha e sutiã ou só de toalha pra ele não ficar me olhando, e mesmo assim isso aconteceu. (E1).

Às vezes pergunto pra Deus por que isso aconteceu [...], se foi por causa do meu jeito de andar, meu jeito de vestir, de falar. (E2).

Eu me sinto culpada e ainda não sei dizer o porquê. (E3).

Igualmente, evidenciou-se a baixa autoestima, a insegurança, o sentimento de inferioridade e a autoimagem negativa. Elas carregam a sensação constante de que, haja o que houver, sempre serão sujas, indignas e depreciáveis pela situação que vivenciaram. Conforme fala das entrevistadas: 
A gente casa com um homem que diz que vai cuidar de você, só que ele mesmo é quem te machuca. (E1).

Isso me machuca muito, sabe, ele me usou e depois jogou pra lá como se eu fosse uma coisa. (E2).

[...] pobre, preta e feia, agora também estuprada [...]. Vem esse homem acabar de desgraçar a minha vida. (E3).

O Ministério da Saúde (BRASIL, 2002) confirma que as vítimas de violência sexual apresentam autoimagem negativa, o que faz com que tenham dúvidas acerca de seu valor, capacidade e desempenho. Além disso, também desenvolvem um estado emocional com um padrão de afeto deprimido, insegurança, desamparo e retraimento social.

Foi identificada a presença de sintomas de Transtorno de Estresse Pós-Traumático em E1, E2 e E3. Destarte, para o diagnóstico do TEPT é necessária a avaliação de um profissional da área. Os sintomas observados são: lembranças e/ou imagens intrusas que acarretam sensação de muita angústia, dificuldades para dormir e pesadelos, irritabilidade, sentimentos de desamparo, resposta exagerada de sobressalto, sentimento de futuro abreviado (estreitamento de horizontes na vida) e esquiva emocional:

Quando ouvia qualquer barulho, já pulava da cama, pensava que era ele [...]. Não conseguia dormir e, quando dormia, era pesadelo direto [...]. Olha, eu tenho pesadelo até hoje [...], pra esquecer queimei colchão, cama, troquei os móveis da casa, se pudesse mudava de casa [...]. Não deixo que o homem fique em cima de mim durante a relação sexual, lembro na hora da imagem do meu marido quando me estuprava. (E1).

Me sinto seguida na rua e isso me assusta. Um dia à tarde liguei pro meu amigo encontrar comigo porque senti que tinha um carro me seguindo[...]. Não contei pra minha família o que aconteceu, até hoje eles não sabem [...]. Agora frequento só festa de família [...]. Estava me guardando para um homem que me amasse, só que homem não ama mulher, né, eles amam sexo. (E2).

Brigava muito com meu irmão, daí ele me chamava de 'estrupadinha', isso acabava comigo [...]. Teve um dia que um amigo me chamou para sair, quando chego na rua ele tava de fusquinha, e branco ainda, falei 'eu não entro aí nem morta, [...]. Eu tinha o sonho de casar virgem, ele roubou isso de mim, roubou minha inocência [...]. Às vezes ainda sinto o cheiro daquele homem no meu corpo, então tomo banho com água sanitária. (E3).

A depressão foi citada nos três casos. Os sentimentos de desesperança, desespero, desamparo, impotência e autoacusação propiciaram um estado depressivo. Scarpato (2004) explica que geralmente as reações pós- 


\section{ADVistg all paUtg}

\} AS CONSEQUÊNCIAS PSICOSSOCIAIS DA VIOLÊNCIA SEXUAL - FREITAS, M. L.; FARINELLI, C. A. \}

DOI: $10.12957 /$ REP.2016.25400

trauma seguem duas direções básicas: depressão (estado depressivo) e ansiedade (estado ansioso e agitado). Entretanto, há pessoas que se alternam entre estes dois estados. Para Jacob (2009), a depressão, juntamente com o estresse pós-traumático, é o sintoma mais comum decorrente da violência sexual.

A raiva e hostilidade reprimidas, que normalmente provocam irritabilidade constante ou explosões de raiva e atos agressivos, os quais são canalizados pela inabilidade em lidar com tais sentimentos, não foram identificados em E2; todavia, bastante evidenciados em E1 e E3:

Tenho ódio dele [...]. Tentei matar ele duas vezes, com chumbinho e remédios. (E1).

Fiquei sem conversar com minha mãe por muitos anos [...]. Por que ela não entrou na frente e impediu ele de me levar? Ninguém fez nada. (E3).

Queixas somáticas foram relatadas por E1, E2 e E3, dentre elas, falta de apetite, náuseas, dor de cabeça, problemas gástricos e sensação de desmaio. Conforme os relatos de Filho e Sougey (2001), estes sintomas compreendem um estado ansioso. São comuns, porém menos específicos, como taquicardia, respiração curta ou suspirosa, sudorese, cefaleias, sensação de oco na cabeça, tonturas, peso no estômago e outros.

A partir dos relatos das entrevistadas verificou-se que há uma tendência ao retraimento social, assim como dificuldade para manter um relacionamento amoroso. Contudo, não podem ser analisados senão com um acompanhamento mais duradouro de cada caso. Além disso, vale ressaltar que muitas mulheres vítimas de violência por meios e caminhos os mais distintos, com ou sem ajuda de profissionais especializados, podem ressignificar estas vivências, até mesmo para continuar a existir socialmente.

De acordo com a literatura, as vítimas encontram dificuldades em confiar no sexo oposto e têm medo de se envolver emocionalmente. A partir das reflexões de Jacob (2009), citando Dillilo, Oely e Hunsley, explicase que as vítimas de violência sexual apresentam menor satisfação nos relacionamentos por possuírem menor grau de confiança em seus parceiros, tendo dificuldade em dividir confidências e discutir preocupações pessoais dentro do relacionamento. Segundo o autor, apresentam ainda falta de envolvimento emocional e um sentimento de isolamento em relação às pessoas, um senso de alienação e introversão social.

Não me permito apaixonar [...]; homem não gosta de mulher boazinha. Se eu fizer isso vou sofrer, vou voltar a ser aquela menina ingênua que foi estuprada [...]. Homem é assim mesmo, gosta de usar a gente, então eu vou lá e uso eles primeiro. (E3). 


\section{ReVistg ell pautg}

\} AS CONSEQUÊNCIAS PSICOSSOCIAIS DA VIOLÊNCIA SEXUAL - FREITAS, M. L.; FARINELLI, C. A.

DOI: $10.12957 / R E P .2016 .25400$

Observou-se a presença de disfunção sexual em E1, E2 e E3, todavia, de modos distintos: E2 apresenta diminuição de interesse por atividades sexuais; em contrapartida, E1 e E3 apresentam compulsão sexual com requintes sadomasoquistas. Segundo Souza (2013), emoções sentidas durante e imediatamente após a violência sexual são consideradas fortes mediadoras da permanência das disfunções sexuais.

A diminuição de interesse por atividades sexuais por parte de E2 pode ser explicada a partir das considerações de Jacob (2009) De acordo com a autora, a excitação sexual, que muitas vezes é uma forma natural de resposta do corpo a um estímulo, não é fácil de ser integrada e compreendida pelas vítimas de estupro, levando-as a associar sexo com algo ruim (considerando a violência sofrida). Assim, buscam formas de evitar sensações sexuais e atos sexuais, normalmente bloqueando se não todas pelo menos as mais intensas sensações alusivas ao sexo.

Tentei me relacionar com um rapaz de outro estado, nosso contato era pela internet [...]. Um dia ele começou a fazer perguntas sobre sexo, disse que precisava me conhecer melhor, queria um sexo virtual [...]. Eu não quis mais manter contato com ele. (E2).

Já a compulsão sexual evidenciada em E1 e E3 é um comportamento resultante da hipersexualização e de fatores psicológicos que, segundo Jacob (2009), tornam-se tentativas de resgatar a autoestima, atenção e sensação de poder e controle. Souza et al. (2013) contribuem com as informações precedentes ao abordar que as vítimas de violência sexual, quando praticam com maior frequência relações sexuais, fazem-no na tentativa de adquirir controle sobre a própria vida sexual. Tal atitude leva as vítimas a tratarem seus corpos de forma perigosa, procurando contato sexual desconectado de relacionamentos amorosos.

Gosto de umas coisas muito loucas, tipo assim, se eu tiver no meio de uma festa e eles acharem que eu sou santinha, aí eu quero ser a piranha da festa [...]. Tenho a necessidade de mostrar pro homem que sou uma mulher sem vergonha. Se eu transar com um cara hoje e conhecer outro amanhã, ou se conhecer no mesmo dia e tiver com vontade de transar com ele, isso pra mim não é problema nenhum, fico com ele também [...]; não tenho limite, só me preocupo de usar camisinha. (E3).

Cabe ressaltar que pode ser difícil compreender como uma mulher que sofreu violência sexual pode desenvolver um comportamento hipersexualizado ou uma compulsão sexual, já que o esperado seria a aversão. Jacob (2009) explica que, nestes casos, deve-se lembrar de que tais mulheres provavelmente apresentam uma cisão em suas personalidades, desenvolvendo uma sexualidade superficial, assim como outros sentimentos. 


\section{ADVistg all paUtg}

\} AS CONSEQUÊNCIAS PSICOSSOCIAIS DA VIOLÊNCIA SEXUAL - FREITAS, M. L.; FARINELLI, C. A. \}

DOI: $10.12957 /$ REP.2016.25400

Concernente à tendência ao sexo violento e/ou sadomasoquista, os quais foram evidenciados em E1 e E3, isto se deve ao fato de que, na verdade, o que as excita é o sentimento de poder sobre o outro, vivenciando, assim, uma troca de papéis em relação à violência sofrida. Além disso, assumem a posição masoquista ou de submissão porque faz com que removam temporariamente a culpa que bloqueia a entrega sexual, conforme relata Jacob (2009).

Não gosto de sexo com carinho, não deixo que os homens beijem e acariciem meus peitos e minha vagina [...]. Gosto de fazer sexo em posições onde tenho controle [...], uso algemas, velas [...], assim me vingo deles. (E1).

Sexo pra mim tem que ser brutal, carícias me irritam, gosto de homem que me dá tapa na cama [...] e quanto mais ele me dá sexo mais eu quero [...]. Quando eles falam que não dão conta mais, isso é a minha maior felicidade. (E3).

Verificou-se que E1, E2 e E3 interromperam o tratamento psicoterápico como uma estratégia de fuga, por não darem conta de assimilar os sentimentos dolorosos ao relembrarem o evento traumático durante as sessões. De acordo com Waldo Filho e Sougey (2001), as estratégias de fuga utilizadas pelas vítimas a fim de minimizar a angústia e o terror provocado pela lembrança do evento traumático advêm da esquiva ativa de pensamentos, sentimentos, conversas, situações e atividades associadas ao trauma (esquiva emocional). São mecanismos de defesa contra a ansiedade gerada pelo fenômeno intrusivo, acompanhados de abundante sofrimento.

Concomitantemente, identificou-se, nos relatos das entrevistadas, que elas não percebiam uma intervenção efetiva dos profissionais envolvidos:

[...] pedia para conversar sobre o acontecido, então eu falava e chorava e ela dizia: com o tempo isso vai passar. Era sempre a mesma coisa e nada melhorava. (E1).

[...] o psicólogo?! Deus é meu melhor psicólogo. (E2).

Ele não olhava nos meus olhos, ele conversava comigo olhando para os meus peitos, sempre tive muito peito, e isso me dava um ódio. (E3).

Neste sentido, o Ministério da Saúde (BRASIL, 2002) aponta que, no caso de violência sexual, a mulher pode estar assustada, traumatizada e emocionalmente ferida. Seus limites precisam ser respeitados. Cada pessoa tem seu tempo próprio de amadurecimento. A pressa do profissional em alcançar resultados imediatos pode intimidar o paciente ou paralisá-lo. Parcimônia e comprometimento devem ser considerados na atuação daqueles que têm como público a mulher vítima de violência. 


\section{Considerações finais}

A violência sexual é uma das mais antigas e amargas expressões da violência de gênero, além de representar uma inaceitável e brutal violação dos direitos humanos das mulheres. Este tipo de violência expõe a mulher a sérios problemas físicos e consequências de ordem psicológica e social, o que pode ter justificado a dificuldade da pesquisa empírica no que se refere à abertura das instituições para a pesquisa.

Mediante estudo, foi possível verificar que as consequências psicossociais da violência feminina são muitas, sendo as principais: depressão, sintomas essencialmente característicos do Transtorno de Estresse Pós-Traumático, tendências ao retraimento social, dificuldade de manter relacionamento amoroso e disfunção sexual. Embora notório a necessidade de apoio e atendimento especializado, constatou-se que a maioria das vítimas abandona o tratamento psicoterápico por não perceber uma intervenção de fato por parte dos profissionais, além de sentir angústia por trazer à tona, nas sessões, as lembranças da violência sofrida.

Diante dos fatos supramencionados, sugere-se que sejam realizados estudos científicos empíricos direcionados a avaliar o fenômeno em questão, bem como a eficácia, eficiência e efetividade dos serviços prestados na Rede Integrada de Atendimento à Mulher Vítima de Violência. Uma vez identificada a necessidade, seja provocada junto ao poder público a efetivação das diretrizes constantes na Política de Enfrentamento à Violência Contra Mulheres, a qual prevê a capacitação dos profissionais e atores que atendem ou tenham contato com pessoas vítimas de violência nas diferentes etapas do processo. Isso inclui profissionais da saúde, delegacias, psicólogos e assistentes sociais.

O atendimento psicossocial a essas mulheres possui características próprias e demanda que os profissionais tenham formação continuada e específica, para que possam atuar e intervir na perspectiva de fortalecimento da mulher, ajudando a enfrentar os conflitos e os problemas inerentes à violência sexual sofrida. Cabe ressaltar, ainda, que, considerando especificamente a atuação do assistente social, esta temática tem sido relevante e muito presente no cotidiano deste profissional, já que a violência sexual constitui uma das manifestações da questão social e, portanto, parte da matéria-prima de seu trabalho. Todavia, devido a suas nuances, constituise numa realidade densa de desafios. A falta de conhecimento dos profissionais sobre a temática prejudica de modo imensurável sua atuação junto às vítimas.

Neste sentido, torna-se imprescindível aos assistentes sociais compreender as consequências psicossociais provenientes da violência sexual, bem como a subjetividade constituída após a agressão, pois as mulheres formam uma barreira, geralmente embutida de vergonha, constrangimento, insegurança e medo, o que representa um empecilho ao atendimento. Tais 


\section{ReVistid all pautg}

\} AS CONSEQUÊNCIAS PSICOSSOCIAIS DA VIOLÊNCIA SEXUAL - FREITAS, M. L.; FARINELLI, C. A.\}

DOI: $10.12957 /$ REP.2016.25400

conhecimentos contribuirão para que os assistentes sociais realizem intervenções propositivas, criativas e qualificadas, pautadas na análise crítica, porém, respeitando as especificidades dos casos.

Não obstante, as demandas que são postas ao assistente social estão cada dia mais complexas; ele deve buscar novas formas de executar seu trabalho direcionando seu envolvimento com a área interdisciplinar, um espaço de troca mútua entre várias especificidades do conhecimento, agregando a ciência no seu fazer profissional e propiciando o desvendamento da complexidade de suas demandas, bem como um modo de ultrapassar seus limites profissionais. 
heVistg all paltg

\} AS CONSEQUÊNCIAS PSICOSSOCIAIS DA VIOLÊNCIA SEXUAL - FREITAS, M. L.; FARINELLI, C. A.\}

DOI: $10.12957 / R E P .2016 .25400$

\section{Referências}

ASSOCIAÇÃO AMERICANA DE PSIQUIATRIA. Manual de diagnóstico e estatísticos de transtornos mentais (DSM IV). Porto Alegre: Artes Médicas. 1995.

ANDRADE, L. H.; VIANA, M. C.; SILVEIRA, C. M. Epidemiologia dos transtornos psiquiátricos na mulher. Revista de Psiquiatria Clínica, São Paulo, v. 33, n. 2. 2006. Disponível em: <http://www.hcnet.usp.br/ipq/revista/ vol33/n2/43.html>. Acesso em: 15 jul. 2014.

DANTAS-BERGER, S. M.; GIFFIN, K. A violência nas relações de conjugalidade: invisibilidade e banalização da violência sexual? Cadernos de Saúde Pública, Rio de Janeiro, v. 21, n.2, mar./abr. 2005. Disponível em: <http://www.scielo.br/scielo.php?pid=S0102-311X2005000200008\&s cript=sci_arttext>. Acesso em: 15 ago. 2014.

BIELLA, J. L. Mulheres em situação de violência: políticas públicas, processo de empoderamento e a intervenção do assistente social. Trabalho de Conclusão de Curso (Graduação em Serviço Social) Universidade Federal de San-ta Catarina (Ufsc), Florianópolis. 2005. Disponível em: <http:// tcc.bu.ufsc.br/Ssocial286678.pdf> Acesso em: 20 jul. 2014.

BRASIL. Código penal. Decreto-Lei n. 2.848, de 7 de dezembro de 1940. 1940. Disponível em: <http://www.planalto.gov.br/ccivil_03/Decreto-Lei/ Del2848.htm>. Acesso em: 20 ago. 2014.

. Código de ética do/a assistente social. Lei n. 8.662/93, dispõe sobre a regulamentação da profissão. Brasília: Conselho Federal de Serviço Social. 2012.

. Lei n. 11.340, de 07 de agosto de 2006. Dispõe sobre a criação dos juizados de violência doméstica e familiar contra a mulher e dá outras providências. Brasília: Diário Oficial da União, 08 ago. 2006.

. Ministério da Saúde. Secretaria de Atenção à Saúde. Departamento de Ações Programáticas Estratégicas. Área técnica de Saúde da Mulher. Prevenção e tratamento dos agravos resultantes da violência sexual contra mulheres e adolescentes. Norma técnica. Brasília: MS. 2005.

- Ministério da Saúde. Secretaria de Políticas de Saúde. Violência intrafamiliar: orientações para prática em serviço. Brasília: MS. 2002.

CASSADO, D. da C.; GALLO, A. E.; ALBUQUERQUE, L. C. Transtorno de estresse pós-traumático em mulheres vítimas de violência doméstica: um estudo piloto. Revista de Psicologia da Unesp, Assis (SP), v. 2, n. 1. 2003. Disponível em: <http://www2.assis.unesp.br/revpsico/index.php/revista/ article/viewFile/18/36>. Acesso em: 04 mai. 2014. 


\section{ReVista dill pautg}

\} AS CONSEQUÊNCIAS PSICOSSOCIAIS DA VIOLÊNCIA SEXUAL - FREITAS, M. L.; FARINELLI, C. A. \}

DOI: $10.12957 /$ REP.2016.25400

CERRUTI, M. Q.; ROSA, M. D. Em busca de novas abordagens para a violência de gênero: a desconstrução da vítima. Revista Mal-Estar e Subjetividade, Fortaleza (CE), v. 8, n. 4, dez. 2008. Disponível em: <http://pepsic.bvsalud. org/pdf/malestar/v8n4/09.pdf>. Acesso em: 20 maio 2014.

CHAUÍ, M. Repressão sexual: essa nossa (des)conhecida. São Paulo: Brasiliense. 1984.

COSTA, J. F. Violência e psicanálise. Rio de Janeiro: Graal. 2003.

COSTA, M. T. da; SANTOS, S. M. dos S. e. Violência doméstica contra as mulheres e seus efeitos emocionais. Monografia (Pós-Graduação do Programa de Pós-Graduação em Psicologia) - Faculdade Martha Falcão (FMF), Manaus. 2008. Disponível em: <http://www.professorthometavares.com.br/ downloads/Relatorio $\% 20$ - $\% 20$ A $\% 20$ Violencia $\% 20$ domestica $\%$ 20contra\%20as\%20mulheres.pdf>. Acesso em: 04 abr. 2014.

DREZETT, J. Violência sexual contra a mulher e impacto sobre a saúde sexual e reprodutiva. Revista de Psicologia da Unesp, Assis (SP), v. 2, n. 1. 2003. Disponível em: <http://www2.assis.unesp.br/revpsico/index.php/ revista/article/viewFile/13/26>. Acesso em: 11 maio 2014.

. Aspectos biopsicossociais da violência sexual. In: Reunión Internacional Violencia: Etica, Justicia y Salud para la Mujer. Monterey. 2000.

ELY, F. R. Serviço Social e interdisciplinaridade. Revista Katálysis, Florianópolis, v. 6, n. 1, jan./jun. 2003. Disponível em: <http://www.redalyc.org/ pdf/1796/179618281013.pdf>. Acesso em: 15 set. 2013.

FIGUEIRA, I.; MENDLOWICZ, M. Diagnóstico do transtorno de estresse pós-traumático. Revista Brasileira de Psiquiatria, São Paulo, v. 25. 2003. Disponível em: <http://www.scielo.br/pdf/rbp/v25s1/a04v25s1.pdf>. Acesso em: 25 jul. 2014.

FÓRUM BRASILEIRO DE SEGURANÇA PÚBLICA. Anuário Brasileiro de Política Pública. São Paulo, ano 7. 2013. Disponível em: <http://www.fo rumseguranca.org.br/storage/download//anuario_2013-corrigido.pdf>. Acesso em: 22 ago. 2014.

FOUCAULT, M. História da sexualidade l: a vontade de saber. Rio de Janeiro: Graal. 1999.

FORWARD, S. Homens que odeiam suas mulheres e as mulheres que os amam. Rio de Janeiro: Rocco. 1989.

GIFFIN, K. Violência de gênero, sexualidade e saúde. Cadernos de Saúde Pública, Rio de Janeiro, v. 10, n. 1. 1994. Disponível em: <http:// www.scielo. br/pdf/csp/v10s1/v10supl1a10.pdf>. Acesso em: 10 maio. 2014.

GUERRA, Y. A instrumentalidade do Serviço Social. São Paulo: Cortez. 2011. 


\section{ReVistg ell pautg}

\} AS CONSEQUÊNCIAS PSICOSSOCIAIS DA VIOLÊNCIA SEXUAL - FREITAS, M. L.; FARINELLI, C. A. \} DOI: $10.12957 /$ REP.2016.25400

IAMAMOTO, M. V. O Serviço Social na contemporaneidade: trabalho e formação profissional. São Paulo: Cortez. 2010.

IPEA, INSTITUTO DE PESQUISA ECONÔMICA APLICADA. Sistema de Indicadores de Percepção Social (Sips). Tolerância social à violência contra as mulheres. 2014. Disponível em: <http://www.ipea.gov.br/portal/images/ stories/PDFs/SIPS/140327_sips_violencia_mulheres_antigo.pdf $>$. Acesso em: 12 jul. 2014.

JACOB, P. Um estudo sobre o abuso sexual e suas consequências nos relacionamentos amorosos. Monografia (Programa de Especialização em Terapia de Família e Casal) - Centro de Estudos da Família e do Indivíduo (Cefi), Cuibá. 2009. Disponível em: <http://www.ebah.com.br/content/ ABAAAA9QkAF/a-ferida-invisivel-estudo-sobre-abuso-sexual-suasconsequencias-nos-relacionamentos-amorosos>. Aceso em: 20 ago. 2014.

MARQUES, M. T. C.; RAMALHO, M. P. Os movimentos ecológicos e a interdisciplinaridade. In: MARTINS, J. L. de S. (Org.). Serviço Social e interdisciplinaridade: dos fundamentos filosóficos à prática interdisciplinar no ensino, pesquisa e extensão. São Paulo: Cortez. 2002.

MINAYO, M. C. de S; SOUZA, E. R. de. Violência e saúde como um campo interdisciplinar e de ação coletiva. História, Ciências, Saúde - Manguinhos, Rio de Janeiro, v. 4, n. 3, nov. 1997.

MIOTO, R. C. T. Para que tudo não termine como um "caso de família": aportes para um debate sobre violência doméstica. Katálysis, Florianópolis (SC), v. 6, n. 1, jan./jun. 2003. Disponível em: <https://periodicos.ufsc.br/ index.php/katalysis/article/view/7122/6623> Acesso em: 02 ago. 2014.

ORGANIZAÇÂO MUNDIAL DA SAÚDE. Informe mundial sobre La violência y salud. Genebra, 2002.

PEREIRA, A. P. Sexualidade em mulheres vítimas de violência sexual. Dissertação (Mestrado do Programa de Pós-graduação da Faculdade de Ciências Médicas) Universidade Estadual de Campinas (Unicamp), Campinas. 2007. Disponível em: <http://www.bibliotecadigital.unicamp.br/document/ ?code $=v t \mid s 000414377 \& f d=y>$. Acesso em: 15 abr. 2014.

SCARPATO, A. T. Estresse pós-traumático: a situação emocional de pessoas vítimas de violência. Psicologia Brasil, São Paulo, ano 2, n. 6. 2004.

SILVA JÚNIOR, J. N.; BESSET, V. L. Violência e sintoma: o que a psicanálise tem a dizer? Fractal: Revista de Psicologia, Niterói (RJ), v. 10, n. 22, maio/ ago. 2010. Disponível em: <http://www.uff.br/periodicoshumanas/index. php/Fractal/article/view/224>. Acesso em: 12 maio. 2014.

SOUZA, F. B. C. de. Consequências emocionais de um episódio de estupro na vida de mulheres adultas. Dissertação (Mestrado do Programa de PósGraduação em Psicologia Clínica) Pontifícia Universidade Católica de São 


\section{ReVista dill pautg}

\} AS CONSEQUÊNCIAS PSICOSSOCIAIS DA VIOLÊNCIA SEXUAL - FREITAS, M. L.; FARINELLI, C. A. \}

DOI: $10.12957 /$ REP.2016.25400

Paulo (PUC-SP). 2013. Disponível em: <http://www.sapientia.pucsp.br// tde_busca/arquivo.php?codArquivo=16395>. Acesso em: 10 ago. 2014.

SOUZA, F. B. C. de et. al. Aspectos psicológicos de mulheres que sofrem violência sexual. Reprodução e Climatério, São Paulo, v. 27, n. 3. 2013. Disponível em: <http://apps.elsevier.es/watermark/ctl_servlet?_f=10 \&pident_articulo=90220071\&pident_usuario=0 \&pcontactid= \&pident_revista $=385 \& t y=129 \&$ accion $=$ L\&origen $=$ recli\&web=recli.else vier.es\&lan=pt\&fichero $=385 \mathrm{v} 27 \mathrm{n} 03 \mathrm{a} 90220071 \mathrm{pdf001} . \mathrm{pdf}>$. Acesso em: 30 ago. 2014.

STREY, M. V.; AZAMBUJA, M. P.; JAEGER, F. P. Violência, gênero e políticas públicas. Porto Alegre: Edipuc-RS. 2004.

VELLOSO, B. B. A violência contra a mulher no município de Rio das Ostras e a atuação da Casa da Mulher: analisando percalços, limites e potencialidades. Trabalho de Conclusão de Curso (Graduação) Universidade Federal Fluminense. 2013.

VERARDO, M. T. (Org.). Violência no relacionamento "amoroso". Série "Violência de Gênero". São Paulo. 1994. Disponível em: http://www. mulheres.org.br/violencia/documentos/violencia_no_relacionamento_ amoroso.pdf >. Acesso em: 22 ago. 2014.

WALDO FILHO, J. W. S. C.; SOUGEY, E. B. Transtorno de estresse póstraumático: formulação diagnóstica e questões sobre comorbidade. Revista Brasileira de Psiquiatria, São Paulo, v. 23, n. 4. 2001. Disponível em: <http:/ /www.scielo.br/pdf/rbp/v23n4/7170.pdf>. Acesso em: 10 abr. 2014.

Recebido em 16 de dezembro de 2014.

Aprovado para publicação em 30 de janeiro de 2016.

DOI: $10.12957 /$ rep.2016.25400

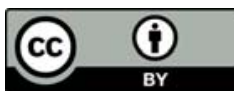

A Revista Em Pauta: Teoria Social e Realidade Contemporânea está licenciada com uma Licença Creative Commons Atribuição 4.0 Internacional. 